\title{
Müziğin Bir Öğretim Aracı Olarak Din Kültürü ve Ahlak Bilgisi Derslerinde Kullanımının Öğrencilerin Akademik Başarı, Tutum ve Bilgiyi Hatırlama Düzeyleri Üzerindeki Etkisi*
}

Using Music as a Teaching Tool in Religion Culture and Moral Knowledge Classes, and Its Effect of on the Academic Achievement, Attitude and Retention Ability of the Students**

Muhammed BABACAN, Sorumlu Yazar, Doktora Öğrencisi, Öğretim Asistan

Bristol Üniversitesi, Sosyoloji Bölümü.

E-mail: mb15488@bristol.ac.uk

ORCID: 0000-0002-8845-4677

ISSN: 1303-880X

e-ISSN: 2667-7504

http://ded.dem.org.tr

Geliş/Received: 03.04.2018

Kabul/Accepted: 03.04 .2018

Makale Yayın: 25.12.2019

Makale Türü/Article Type:

Araştırma/Research
Atıf/Citation: Babacan, M. (2019). Müziğin bir öğretim aracı olarak Din Kültürü ve Ahlak Bilgisi derslerinde kullanımının öğrencilerin akademik başarı, tutum ve bilgiyi hatırlama düzeyleri üzerindeki etkisi. Değerler Ĕ̆itimi Dergisi,17 (38), 105-138. DOI: $10.34234 /$ ded.412282

* Bu çalışma 2015 tarihinde onaylanan "Müziğin Bir Öğretim Aracı Olarak Din Kültürü ve Ahlak Bilgisi Derslerinde Kullanımı" konulu Yüksek Lisans tezim esas alınarak hazırlanmıştır.

** This article is derived from my Master thesis in 2015 called as "The Usage of Music as a Teaching Tool in Religion Culture and Moral Knowledge Classes" 
Öz: Bu araştırmanın amacı, müziğin bir öğretim aracı olarak Din Kültürü ve Ahlak Bilgisi derslerinde kullanımının öğrencilerin akademik başarıları, derse karşı tutumları ve öğrendiklerini hatırlama düzeyleri üzerindeki etkisini incelemektir. Bu amaç doğrultusunda araştırmanın deneysel kısmı, 2013-2014 öğretim yılı güz döneminde İstanbul ilinde MEB’e bağlı iki okulda gerçekleştirilmiştir. Çalışmanın örneklemini 5. sınıfa devam eden 65'i deney, 68'i kontrol olmak üzere toplam 133 öğrenci oluşturmaktadır. Ön test-son test kontrol gruplu karışık deneysel modelin kullanıldığı araştırmada, 2013-2014 öğretim yılının 5.sınıfına ait İbadet Konusunda Bilgilenelim ünitesi ve kazanımları doğrultusunda toplamda 8 hafta süren bir uygulama gerçekleştirilmiştir. Uygulama sürecinde dersler, deney grubunda müzik materyali kullanılarak gerçekleştirilen etkinliklerle, kontrol grubunda Öğretmen Kılavuz Kitabı'nda yer alan öğretim yöntem ve teknikleri ile işlenmiştir. Araştırma verileri; Akademik Başarı Testi ve DKAB Dersi Tutum Ölçeği ile toplanmıştır. Araştırmada elde edilen veriler t-testi ile analiz edilmiş, istatistiksel anlamlılık için .05 anlamlılık düzeyi seçilmiştir. Araştırma sonucunda, deney grubu öğrencileri ile kontrol grubu öğrencilerinin akademik başarıları, DKAB dersine yönelik tutum düzeyleri ve öğrendiklerini hatırlama düzeyleri arasında deney grubu lehine anlamlı derecede fark olduğu tespit edilmiştir. Ayrıca araştırmada, müziğin bir öğretim aracı olarak kullanımının öğrencilerin derse yönelik ilgi, katılım ve motivasyonlarında olumlu etki yarattığ 1 gözlemlenmiştir.

Anahtar Kelimeler: Müzik, Din Kültürü ve Ahlak Bilgisi, Öğretim aracı, Akademik başarı, Kalıcılık, Tutum

$\&$

Abstract: The aim of this research is to examine the effects of using music as a teaching tool in Religion Culture and Moral Knowledge course and examining its effect on academic achievements, attitudes towards the lesson, and recall levels. The empirical part of the research was conducted in two state schools in Istanbul, during the autumn of academic year 2013-2014. The sample of this study consists of 133 fifth grade students, 65 of whom participated in the experiment group, whilst the other 68 were in the control group. The research made use of 'pre-test and post-test experiment-control group mixed-experimental design' to assess the effects of using music as a teaching tool. The test period lasted for 8 weeks in total focusing on the learning goals of the chapter "Let's Learn the Subject of Worship" in 5th grade of 2013-2014 academic year. In the experiment group, the courses were conducted using the teaching methods and techniques that put in 'The Teacher Guidebook', whereas in the control group, 
the courses were conducted using music materials. The data of the research was collected by means of the Academic Achievement Test, 'Religion Culture and Moral Knowledge Course Attitude Measure'. The data obtained from the study was analysed by T-Test and the statistical meaningfulness was chosen , 05 degrees. As a result of the study, the academic achievements, the attitudes towards the course and the retention levels of the experimental group and the control group students were identified to be significantly difference in favour of the experimental group. As well as this, it has been observed that the usage of music as a teaching tool has a positive effect on interests, participations and motivations of students.

Keywords: Music, Religion Culture and Moral Knowledge, Teaching tool, Academic achievement, Retention, Attitude.

\section{Giriş}

Müzik, bir toplumun tarihini, inançlarını, kültürünü, geleneklerini, değerlerini, edebiyatını ve hatta mizah anlayışını yansıtan yönleriyle insan hayatının en önemli unsurlarından biridir. Duyguları uyaran, düşünceleri harekete geçiren, olay ve olguların hatırlanmasını kolaylaştıran müzik, bu özellikleri nedeniyle psikoloji, nörobiyoloji, dilbilim, antropoloji, sosyoloji gibi birçok disiplinin araştırma konusu olmaktadır. Müzik insanların fizyolojik ve psikolojik tedavisinde, dinî ritüellerde, kültürel aktarımda, iletişimde, ideolojilerin benimsetilmesinde, reklam ve pazarlamada, eğlencede vb. birçok alanda bir araç olarak kullanılmaktadır.

Sosyo-kültürel hayatın önemli bileşenlerinden biri olan müziği, tüm dinler belirli formlarda bünyesinde barındırmakta, hatta çoğu din için müzik, merkezi bir önem taşımaktadır (Alcorta and Sosis, 2005). Müzik ve din, neredeyse tarihin her döneminde ve her kültürde belli amaçlar doğrultusunda birbirleriyle etkileşim içerisinde olmuştur (Robin, 2002). Din fitri, tabii ve insani bir olgu olduğu gibi, müzik de fitri, tabii ve insani bir olgudur. Bu noktada dinle musiki kesişmekte ve bir ölçüde örtüşmektedir (Uludağ, 2002). Dinî manayı aktarmak ve dinin etkisini ifade etmek için kullanılan müziği, bu yönüyle insanlığın kullandığı en güçlü araçlardan birisi olarak görebiliriz.

Müzik, batı ülkelerinin çoğunda inanç deneyiminde yeni yollar açmayı başardığı ve dinî tecrübeye yeni alanlar kazandırdığ 1 için din derslerinin kapsamına alınmıştır. Özellikle ilahi veya dinî temalı, dinî gelenek açısından din dersinin 
vazgeçilmez bir parçasıdır. Dinî fenomen ve içerikler, konuşma alışkanlıklarımızla ifade edemeyeceğimiz bir güce sahiptir. Bu bakımdan müzik, öğrencilere dinî materyalleri daha derin bir şekilde anlama imkânı sunduğu gibi, duygu ve düşüncelerini ifade etme firsatı vermektedir.

Müziğin eğitim-öğretim ortamında bir araç olarak kullanımına yönelik fark11 ülkelerde birçok çalışma yapılmış ve öğrenciler üzerinde olumlu bir etkiye sahip olduğu sonucuna varılmıştır. Ancak ülkemizde, müziğin öğretim aracı olarak derslerde kullanımına ilişkin çalışmalara son birkaç yıldır rastlanmaya başlanmıştır. Ayrıca, Milli Eğitim Bakanlığı tarafından hazırlanan derslerin öğretim programlarında müzik destekli etkinliklerinin yeteri kadar yer almadığ1 da görülmektedir.

2004 yılından itibaren Türkiye'de ilköğretim programları yapılandırmacı yaklaşıma göre yenilenmeye başlanmış ve öğrenci merkezli, etkinlik temelli, yatay eksende dersler arası ve dikey eksende her bir dersin kendi içinde ilişkilendirilmesinin dikkate alındığı, öğrencilerin sınıf içi ve sınıf dışı öğrenme deneyimlerini bütünleştirmeye önem veren bir eğitim-öğretim anlayışı benimsenmiştir. Bu bağlamda, belirli bir dersteki öğrenmeler ile diğer derslerin ilişkilendirilmesine vurgu yapıldığı görülmektedir. Ancak MEB'in 2015 yılına kadar ki 4.-8. sınıf DKAB Öğretim Programı incelendiğinde müzik etkinlikleri ile ilişkilendirilen ya da müziğin bir araç olarak kullanımına yönelik olan materyallerin çok yetersiz olduğu tespit edilmiştir (Başkurt, 2012).

Etkili ve verimli araçlardan biri olan müziğin öğrenme-öğretme ortamında kullanılması, sınıfta etkili bir öğretim atmosferi oluşturmaktadır. Öyle ki, araç gereçler, eğitim yaşantılarını zenginleştirmek, öğrenilecek konuların anlaşılmasını kolaylaştırmak ve eğiticinin etkinliğini artırmak amacıyla geliştirilen öğretim malzemeleridir (Alkan, 1979). Öğretim araçları sayesinde, daha fazla duyu organına hitap etme imkanı sağlanır (Varış, 1994), öğrencilerin konulara ilgileri artar (Çilenti, 1998), öğrenme daha çabuk gerçekleşir (Pekgöz ve Hancılar, 1972) ve öğrenilen bilgiler daha kalıcı olur (Fidan ve Erden, 1993).

Araç-gereçlerin defalarca kullanılabilme özelliğinin olması, kavranması zor olan bir konuyu basitleştirerek öğrencilere takdim etme imkanı sunması, bu malzemeleri eğitim-öğretim ortamının vazgeçilmez öğesi haline getirmiştir (Yalın, 2001). Bu anlamda müzik için de, pozitif ve arzu edilen bir sınıf ortamı oluşturan, beyin dalgalarını ve duygusal durumları değiştirerek öğrenmeyi kolaylaştıran, derse güdülenmeyi sağlayan, dikkati artıran, hafızayı geliştiren, gerilimi/gerginliği azaltan, öğrenciler arasında sosyal uyumu sağlayan, disiplin problemlerini azaltan, istek ve motivasyonu artıran ve sonuç olarak öğrenme durumunu eğlenceli hale getiren güçlü bir eğitim-öğretim aracıdır diyebiliriz. 
Müziğin bir öğretim aracı olarak din derslerinde kullanımına yönelik deneysel bir araştırma tespit edebildiğimiz kadarıyla gerek yurt içinde gerekse yurt dışında bulunmamaktadır. Bunun yanı sıra, alanla ilgili yapılmış teorik çalışma ise çok az sayıda bulunmaktadır. Başkurt (2012), yaptığı çalışmada, din dersleri özelinde müzik ve müzik parçalarının eğitimde araç olarak kullanılması hususunu incelemiş ve müziğin motivasyon gücü, duygusal-duyuşsal alanı harekete geçirmesi, din eğitimsel önemi ve din derslerinde kullanım alanları gibi temel konulara dikkat çekmiş̧ir. Aydın (2014), çalışmasında, din öğretiminde resim ve müzikten yararlanılması gerektiği üzerinde durmuş, güzel sanatların, çocuklara düşünme ve yaratıcı güçlerini geliştirmede en elverişli ortamı hazırlayan eğitim alanları olduğunu vurgulamıştır. Yorulmaz (2012), Bir Din Eğitimi Aract Olarak Din̂̂ Müziğin Kullanımı adlı çalışmasında, müziğin çocukların zihinsel, ruhsal, kültürel, sosyal, psiko-motor gelişimine ve çoklu zekâ çerçevesinde müziksel zekâya katkıda bulunduğuna dikkat çekmiş ve eğitimcilerin müziği özellikle okul öncesi ve ilköğretim çağında etkili bir araç olarak kullandığını belirtmiştir.

Öte yandan, Pohlmann (2006), Musik im Religionsunterricht der Grundschu$l e^{14}$ adlı çalışmasında, Almanya'da 1954-2003 yılları arasındaki din derslerinde müziğin kullanım şekillerinin tarihi gelişimini karşılaştırılmalı olarak ele almış, konuyla ilgili pek çok ilahi örneği sunmuştur (Pohlmann, 2006). Berglund (2008), 2005-2006 tarihlerinde İsveç’te Müslümanlara ait bir ilkokulda yapmış olduğu araştırmada, İslam dini eğitimi öğretmeni olan Sana'nın (takma adı) s1nıfında gözlem yapmıştır. Müziğin İslam dininin öğretiminde önemli bir unsur olduğunu dile getiren Berglund, dersin tartışmasız bir parçası veya konusu olduğunu söylemenin ise doğru bir yaklaşım olamayacağına dikkat çekmektedir.

Araştırmada, sınıfta Sami Yusuf gibi Müslüman sanatçıların parçaları çalındığında öğrencilerin müziğin haram veya helal oluşuna dair verdikleri tepkilere de değinmektedir. Örneğin bazı öğrenciler sınıfta çalınan pop müziklerin haram olduğunu ileri sürmüşlerdir. Ancak Sana bu tür tartışmalara girmektense verilmek istenen mesajı karşı tarafa çok daha hızlı ve eğlenceli bir şekilde vermesi nedeniyle müzik materyallerinin kullanımına izin verildiği üzerinde durmuştur. Ona göre, Sami Yusuf'un bazı şarkı sözlerinin iyi bir Müslümanın nasıl davranmas1 gerektiği ve yine Hz. Muhammed'in nasıl iyi bir rol model olduğu konularını ele alması yönüyle dersin amacına ciddi katkılar sunmaktadır. Ayrıca Sana'nın, gençlere rol model olacak Müslüman artistlerin tanıtılması gerekliliğinden de bahsetmektedir (Berglund, 2008). 


\section{Araştırmanın Amacı ve Denenceleri}

Müziğin bir öğretim aracı olarak derslerde kullanımına yönelik çalışmalar yaklaşı son 10 yılda özellikle okuma, yabancı dil, matematik, özel eğitim, okul öncesi eğitim vb. derslerde hızla artmıştır. Ulusal ve uluslararası literatürde yer alan çalışmaların çoğunluğu, müziğin özellikle pedagojik bir değerinin olduğunu ortaya koymaktadır. Müziğin bireyi neredeyse bütün yönleri ile etkilemesi ve güçlü bir öğretim aracı olarak birçok derste kullanılması, bu araştırmanın çıkış noktasını oluşturmaktadır. Bu noktadan hareketle çalışmamızın amacı; "Müziğin bir öğretim aracı olarak Din Kültürü ve Ahlak Bilgisi derslerinde kullanımının öğrencilerin akademik başarılarına, öğrendiklerinin kalıcılığına ve derse karşı tutumlarına etkisi nedir?" sorusunu cevaplamaktır.

Buna göre, problem cümlesine yanıt almak için aşağıdaki denenceler sınanmıştır:

1. Müzik materyalleri kullanılarak oluşturulan ortaokul 5. sınıf Din Kültürü ve Ahlak Bilgisi öğretim etkinliklerinin uygulandığı deney grubu öğrencileri ile 5.sınıf Din Kültürü ve Ahlak Bilgisi dersi öğretim programı öğretmen kılavuz kitabında yer alan etkinliklerin uygulandığı kontrol grubu öğrencilerinin deney öncesinde yapılan ön test başarı puanları arasında anlamlı bir fark yoktur.

2. Deney ve kontrol gruplarında yer alan öğrencilerin uygulama sonunda yapılan son test başarı puanları arasında deney grubu lehine anlamlı bir fark vardir.

3. Deney ve kontrol gruplarında yer alan öğrencilerin ön test ve son test puanları arasında son test lehine anlamlı bir fark vardır.

4. Deney ve kontrol gruplarında yer alan öğrencilerin kalıcılık testi başarı puanları arasında deney grubu lehine anlamlı bir fark vardır.

5. Deney ve kontrol grubu öğrencilerinin deneysel işlem öncesi Din Kültürü ve Ahlak Bilgisi dersi tutum puanları arasında anlamlı bir fark yoktur.

6. Deney ve kontrol grubu öğrencilerinin deneysel işlem sonrası Din Kültürü ve Ahlak Bilgisi dersi tutum puanları arasında deney grubu lehine anlamlı bir fark vardır.

7. Deney grubu öğrencilerinin deneysel işlem öncesinde ve sonrasında aldıkları Din Kültürü ve Ahlak Bilgisi dersi tutum puanları arasında deneysel işlem sonrası lehine anlamlı bir fark vardır.

8. Kontrol grubu öğrencilerinin deneysel işlem öncesinde ve sonrasında aldıkları Din Kültürü ve Ahlak Bilgisi dersi tutum puanları arasında anlamlı bir fark yoktur. 
$\mathrm{Bu}$ araştırmada, din derslerinde bir öğretim aracı olarak müzik materyallerinden yararlanılmasının din dersi öğretmenleri, öğrenciler ve ilgili kurumlar için çok önemli yararlar sağlayacağı düşünülmektedir. Bu bağlamda, araştırmada elde edilecek bulguların; müziğin bir öğretim aracı olarak din derslerinde ciddiyetinin algılanmasını ve kullanılmasını sağlayacağı, MEB'e bağlı ilk ve ortaokul din dersleri öğretim programları yeniden yapılandırılırken müziğin öğretim aracı olarak değerlendirileceği ve konu ile ilgili yapılacak yeni araştırmalara 1şık tutacağı umulmaktadır.

\section{Yöntem}

Araştırmamız, nicel araştırma yöntemleri kullanılarak gerçekleştirilmiştir. Araştırmanın nicel boyutunu ön test-son test kontrol gruplu karışık deneysel bir model oluşturmuş̧tur. Deneysel model, araştırmacının kontrolü altındaki değiş̧kenler arasındaki neden-sonuç ilişkilerini keşfetmek için gözlenmek istenen verilerin üretildiği araştırma alanıdır Deneysel model ile yapılan her araştırmada mutlaka bir karşılaştırma vardır. Bu, belli bir şeyin kendi içindeki değişimleri ya da bunlar arasındaki ayrımların karşılaştırılması anlamında olabilir (Karasar, 2005).

Araştırmamızın örneklem sayısını artırmak amacı ile uygulama iki farklı okulda gerçekleştirilmiştir. Gruplar tesadüfi/random atama yoluyla deney ve kontrol grubu olarak belirlenmiştir. Öğretim, deney grubunda, müzik materyallerinden yararlanarak, kontrol grubunda ise geleneksel yöntemlerle gerçekleştirilmiş̧ir. Uygulama, deney ve kontrol gruplarına ön testin verilmesi ile başlatılmıştır. 8 hafta süren çalışma sonunda her iki gruba da son test uygulanmıştır. Daha sonra öğrencilerin Din Kültürü ve Ahlak Bilgisi dersine karşı tutumlarını incelemek için tutum ölçeği, uygulama öncesi ve uygulama sonrası olmak üzere iki kez tatbik edilmiştir. Diğer yandan deney ve kontrol grubu öğrencilerinin öğrendiklerini hatırlama düzeylerinin saptanması amaciyla son test tarihinden 45 gün sonra deney ve kontrol grubu öğrencilerine kalıcılık başarı testi yapılarak araştırma tamamlanmıştır.

\section{Araştırmanın Deneysel Deseni}

Deneysel desende katılımcılar, deneysel işlemden önce ve sonra bağımlı değişkenle ilgili olarak değerlendirilirler. Ön test-son test kontrol gruplu desen, bu yönüyle ilişkili bir desendir. Çünkü aynı kişilere bağımlı değiş̧ken üzerinden iki 
kez ölçme yapılır. Ayrıca, farklı deneklerden oluşan deney ve kontrol gruplarının ölçümlerinin karşılaştııılması nedeniyle de bu desen ilişsisizdir. Bundan dolayı ön test- son test kontrol gruplu desen karışık bir desendir. Araştırmanın deneysel desenini gösterir tablo aşağıda verilmiştir.

\begin{tabular}{lcclll}
\hline \multicolumn{2}{l}{ Tablo 1: Araştırmanın Deneysel Deseni } & & & \\
\hline Okullar/Şube & Gruplar & Ön Test & Deneysel İşlem & Son Test & Kalıc1lı Testi \\
\hline $\begin{array}{l}\text { A. HamdiTanpınar } \\
\text { Ortaokulu }{ }^{15}-5 / \mathrm{A}\end{array}$ & Deney & $\mathrm{T}^{16}, \mathrm{~T}^{17}$ & $\begin{array}{l}\text { Müzik Materyali } \\
\text { Kullanarak Öğretim }\end{array}$ & $\mathrm{T} 1, \mathrm{~T} 2$ & $\mathrm{~T} 1$ \\
\hline $\begin{array}{l}\text { A. Hamdi Tanpınar } \\
\text { Ortaokulu-5/B }\end{array}$ & Kontrol & $\mathrm{T} 1, \mathrm{~T} 2$ & Geleneksel Öğretim & $\mathrm{T} 1, \mathrm{~T} 2$ & $\mathrm{~T} 1$ \\
\hline $\begin{array}{l}\text { Eyüp Sultan } \\
\text { Ortaokulu }{ }^{18}-5 / \mathrm{E}\end{array}$ & Deney & $\mathrm{T} 1, \mathrm{~T} 2$ & $\begin{array}{l}\text { Müzik Mteryali } \\
\text { Kullanarak Öğretim }\end{array}$ & $\mathrm{T} 1, \mathrm{~T} 2$ & $\mathrm{~T} 1$ \\
\hline $\begin{array}{l}\text { Eyüp Sultan } \\
\text { Ortaokulu-5/C }\end{array}$ & Kontrol & $\mathrm{T} 1, \mathrm{~T} 2$ & Geleneksel Öğretim & $\mathrm{T} 1, \mathrm{~T} 2$ & $\mathrm{~T} 1$ \\
\hline
\end{tabular}

Tablo 1'de de görüldüğü gibi araştırmanın deneysel desenini, iki okuldaki tesadüfi /random atama yoluyla belirlenen deney ve kontrol grupları oluşturmaktadır. Araştırmanın deneysel deseni, araştırmacı tarafından organize edilerek deney ve kontrol gruplarına uygulanmıştır. Uygulamalar sırasında dersin kadrolu öğretmenleri sınıfta gözlemci olarak bulunmuşlardır. Araştırmanın başlangıcında her iki okulda da deney ve kontrol gruplarına ön test olarak İbadet Konusunda Bilgilenelim Ünitesi Başarı Testi (T1) ve Din Kültürü ve Ahlak Bilgisi Dersi Tutum Ölçeği (T2) uygulanmıştır. Deneysel işlemde deney gruplarına müzik materyali kullanarak öğretim gerçekleştirilirken, kontrol gruplarına ise geleneksel öğretim uygulanmıştır. Deneysel işlemin bitiminden 1 hafta sonra İbadet Konusunda Bilgilenelim Ünitesi Başarı Testi (T1) ve Din Kültürü ve Ahlak Bilgisi Dersi Tutum Ölçeği (T2) her iki gruba da son test olarak uygulanmıştır. Son test tarihinden 45 gün sonra, deney ve kontrol gruplarına, kalıcılık düzeyinin belirlenmesi amaciyla İbadet Konusunda Bilgilenelim Ünitesi Başarı Testi (T1) tekrar uygulanmıştır.

\section{Araştırmanın Çalışma Grubundaki Deney ve Kontrol Gruplarının Seçimi}

Yukarıda da belirtildiği gibi, deney ve kontrol gruplarındaki örneklem sayısını artırmak amacı ile uygulama iki farklı okulda gerçekleştirilmiştir. Araştırmanın yürütülebilmesi için belirlenen okulların sosyo-kültürel ve ekonomik özellik-

15 Bundan sonra (A Okulu).

16 T1: İbadet konusunda bilgilenelim ünitesi başarı testi.

17 T2: Din kültürü ve ahlak bilgisi dersi tutum ölçeği.

18 Bundan sonra (B Okulu). (dipnotların paragraf düzeni asılı olsa daha mı iyi olur) 
lerinin evreni en iyi şekilde yansıtabilmesine dikkat edilmiştir. Ayrıca, belirlenen okullarda en az iki adet 5. sınıf şubesinin olması ve Din Kültürü ve Ahlak Bilgisi öğretmenlerinin alanlarında en az 5 yıl deneyim sahibi olmaları gibi ölçütlere de dikkat edilmiştir. Deneysel çalışmalarda, uygulama öncesi deney ve kontrol gruplarının başarı düzeylerinin birbirine denk olması, araştırmanın sağlıklı yürütülebilmesi açısından önemlidir. Bu nedenle her iki okulda da gruplar belirlenirken din kültürü ve ahlak bilgisi dersi branş öğretmenleri ve rehber öğretmenlerin görüşleri alınmış, başarı düzeyleri birbirine yakın olan şubeler belirlenerek deney ve kontrol grupları rastgele seçilmiştir. Çalışma gruplarını oluşturan öğrencilerin okul ve cinsiyete göre dağılımı Tablo 2'de gösterilmiştir.

\begin{tabular}{|c|c|c|c|c|}
\hline Okullar & Gruplar & Cinsiyet & $\mathrm{n}$ & Toplam \\
\hline \multirow{4}{*}{ A Okulu } & \multirow{2}{*}{ Deney } & $\mathrm{K} 1 \mathrm{z}$ & 18 & \multirow[t]{2}{*}{41} \\
\hline & & Erkek & 23 & \\
\hline & \multirow{2}{*}{ Kontrol } & $\mathrm{K} 1 \mathrm{z}$ & 19 & \multirow[t]{2}{*}{43} \\
\hline & & Erkek & 24 & \\
\hline \multirow{4}{*}{ B Okulu } & \multirow{2}{*}{ Deney } & $\mathrm{K} 1 \mathrm{z}$ & 13 & \multirow[t]{2}{*}{24} \\
\hline & & Erkek & 11 & \\
\hline & \multirow{2}{*}{ Kontrol } & $\mathrm{K} 1 \mathrm{z}$ & 14 & \multirow[t]{2}{*}{25} \\
\hline & & Erkek & 11 & \\
\hline \multirow{4}{*}{ Genel Toplam } & \multirow{2}{*}{ Deney } & $\mathrm{K} 1 \mathrm{z}$ & 31 & \multirow[t]{2}{*}{65} \\
\hline & & Erkek & 34 & \\
\hline & \multirow{2}{*}{ Kontrol } & $\mathrm{K} 1 \mathrm{z}$ & 33 & \multirow[t]{2}{*}{68} \\
\hline & & Erkek & 35 & \\
\hline
\end{tabular}

Tablo 2'deki verilere göre, okullarda deney ve kontrol grubunu oluşturan öğrenciler nicelik olarak yakın bir dağılım göstermektedir. Örneklemi oluşturan öğrencilerin cinsiyetlere göre dağılımlarına bakıldığında deney grubunda $31 \mathrm{kız}$ ve 34 erkek öğrenci, kontrol grubunda ise 33 kız ve 35 erkek öğrenci bulunmaktadır. Buna göre, araştırmanın uygulama sürecine katılan öğrenci sayısı toplam 133’tür.

\section{Müzik Materyallerinin Hazırlanması Süreci}

Ünite kazanımlarının belirlenmesinden sonra deneysel uygulama sürecinde kullanılacak müzik materyallerinin tespitine geçildi, bu sebeple çeşitli ilahi kitapları incelendi ve internet kaynakları tarandı. Ancak üniteye uygun müzik materyali bulunamadığı için araştırmacı tarafından "İbadet Ederiz", "İbadettir İbadet”, "İbadet Kavramları", "Canım Benim” ve "Dua” başl1kl 5 güfte yazılmıştır. Güfteler yazılırken, ortaokul 5. sınıf gelişim ve eğitim düzeyine uygunluğu ve öğrencilerin kazanımlara daha etkili bir şekilde ulaşabilmeleri husus- 
larına dikkat edilmiştir. Yazılan güfteler uzman görüşü alındıktan sonra Fatih Atatürk İmam Hatip Ortaokulu'ndaki 5 öğrenci tarafından ritim tutturularak seslendirilmiştir. Güftelerin seslendirilmeleri, Türkiye İzcilik Federasyonu'nda da benzer çalışmalar yapmaları nedeniyle söz konusu öğrencilere yaptırılmış ve seslendirme kayıt altına alınmıştır. Tablo 3 ’te yazılmış olan güfteler ile ilgili kısa örnekler görülmektedir.

Tablo 3: Yazılan Güftelerden Bazı Kısa Örnekler

İbadettir İbadet
Herkese selam vermek, güler yüzlü görünmek
Faydalı insan olmak ibadettir ibadet
Anne babayı sevmek, iyilikte bulunmak
Onlara dua etmek ibadettir ibadet

\section{Canım Benim}

Beş vakit Namaz kılmak

Başında Abdest almak

Otuz gün oruç tutumak

Elbette farzdır canım
İbadet kavramları

Allah'in emridir farz yapmalıyız her zaman Farzları inkâr etmez Müslüman olan insan Sevap kazanır yapan yapmayana günah var Rabbin bizden isteği uyanlara cennet var

\section{Dua}

Sevinçte üzüntüde şükür ve her işte biz Her yerde her dilde tek Rabbimizden isteriz Sadece sözle olmaz çalışmak zorundayız Allah'ı sıkça anıp ibadet etmeliyiz

\section{Veri Toplama Araçları ve Geliştirilmeleri}

\section{İbadet konusunda bilgilenelim ünitesi başarı testi}

$\mathrm{Bu}$ test, ortaokul 5. sınıf öğrencilerinin İbadet Konusunda Bilgilenelim ünitesinde öğrendikleri kazanımları ölçmek için kullanılmıştır. Başarı testinin hazırlanması, geliştirilmesi ve uygulanması sürecinde öncelikle ünitenin kazanımları, MEB tarafından belirlenen kazanımlar dikkate alınarak belirlenmiştir. Daha sonra, İbadet Konusunda Bilgilenelim ünitesinin kazanım düzeylerini ölçmek için başarı testi hazırlanmıştır. Söz konusu test hazırlanırken, MEB tarafından önerilen ders kitaplarında (Millî Eğitim Bakanlığı, 2010 ve 2013) ve Din Kültürü ve Ahlak Bilgisi dersi ile ilgili çeşitli materyaller sunan web sitelerinde yer alan benzer değerlendirme sorularından yararlanılmıştır.

Hazırlanan başarı testinin ön deneme uygulaması için Fatih, Kağıthane ve Esenyurt'tan birer okul seçilmiştir. Başarı testi bu okullara devam eden ve İbadet Konusunda Bilgilenelim ünitesini işlememiş olan 4. sınıf öğrencileri ile aynı üniteyi işlemiş olan 6. sınıf öğrencilerinden oluşan toplam 238 öğrenciye uygulanmıştır. Başarı testinin 4. ve 6. sınıf öğrencilerine uygulanmasının nedeni, 4. sınıf öğrencilerinin söz konusu üniteyi işlememiş olmaları, 6. sınıf öğrencilerinin ise üniteyi işlemiş olmalarıdır. Buna göre, başarı testimizin ünite konuları$\mathrm{n}$ bilen öğrenciler ile bilmeyen öğrencileri ayırt etmesi beklenmektedir. Pilot 
uygulama sonunda testin güvenirlik katsayısı ile yapılan istatistiksel analizde, testin Cronbach Alpha değeri 0.71 olarak bulunmuştur. 45 maddenin/sorunun SPSS 16 paket programı ile yapılan madde analizleri sonucu madde-bütün (item-total) ilişkileri incelenmiş, ölçme tekniklerine uygun düşmeyen 3 soru testten çıkarılmıştır. Kalan 42 madde tekrar işleme sokulduğunda testin Cronbach Alpha değeri 0.74 olarak hesaplanmıştır. Kalaycı'ya göre, testlerde Alpha katsayısına bağlı olarak ölçeğin güvenirliği $0.60 \leq \mathrm{a}<0.80$ ise ölçek oldukça güvenilir bir ölçektir (Kalayc1, 2009).

Daha sonra pilot uygulamada kullanılan 42 sorunun her biri için Madde Güçlük ve Madde Ayırt Edicilik indeksleri hesaplanmıştır. Öğrencilerin başarı düzeyleri hakkında bilgi toplama için kullanılacak bir testin ortalama güçlüğü 0,50 civarında olmalıdır. Çünkü orta zorluktaki bir test daha ayırt edici olduğu halde çok kolay ve çok zor testler yeterince ayırt edici değildir. Testi oluşturan maddeler seçilirken zayıf öğrenciyle iyi öğrenciyi birbirinden ayırt etme gücü değerlerine bakılır. Bu değerler üst grup ile alt grup arasındaki farkları gösterir. Bu fark ne kadar büyükse sorunun geçerliliği ve testin bütünü ile arasındaki ilişki de o kadar yüksek olur. Ayırt etme gücü 0,40 ve daha büyük olan maddeler, ayırt etme gücü yüksek olan maddelerdir. 0,20-0,29 arasında ayırt etme gücüne sahip olan maddelerin ayırt etme gücü orta, ayırt etme gücü 0,19 ve daha küçük olan maddelerin ise ayırt etme gücü düşüktür (Turgut, 1977).

Madde güçlük ve ayırt edicilik indekslerinin hesaplanmasından sonra istenilen değer aralıklarında bulunmayan toplam 3 madde/soru daha testten çıkarılmıştır. Madde güçlük ve ayırt edicilik indekslerine göre testten çıkarılan sorulardan sonra test 39 maddeye/soruya düşmüştür.

\section{Din kültürü ve ahlak bilgisi dersi tutum ölçeği}

Öğrencilerin Din Kültürü ve Ahlak Bilgisi dersine ilişkin tutumlarını ölçmek için kullanılan "Din Kültürü ve Ahlak Bilgisi Dersi Tutum Ölçeğì”, Zengin (2013) tarafından geliştirilmiş̧ir. Zengin, tutum ölçeğinin geliştirilmesi aşamasında Kaya (2001) ve Arıcı'nın (2008) geliştirmiş olduğu tutum ölçekleri ile farklı disiplinlerde hazırlanan tutum ölçeklerinden yararlanmıştır. 19 maddeden oluşan beşli Likert tipi yeni bir ölçek elde edilmiş, ölçeğin geçerlik ve güvenirlik çalışmaları yapılmış ve 4 madde ölçekten çıkarılmıştır. Ölçeğin KMO (Kaiser-Meyer-Olkin) değeri 0,94, Barlett test değeri ise 21035,025 olarak bulunmuştur. Bu değerler, ölçeğin faktör analizi için uygun ve örneklemden elde edilen verilerin yeterli olduğuna işaret etmektedir. Cronbach's Alpha Katsayıs1nın 0,905 olması, tutum ölçeğinin güvenilir olduğunu göstermektedir. 
Beşli bir dereceleme kategorisine sahip olan ölçekte tutumlar; Kesinlikle kat1lyorum $=5$ puan, Katılıyorum $=4$ puan, Az katılıyorum $=3$ puan, Katılm1yorum $=2$ puan, Kesinlikle katılmıyorum $=1$ puan şeklinde belirlenmiştir. Ölçekteki olumsuz ifadelerin puanlanması ise tersinden belirlenmiştir. Buna göre, öğrencilerin Din Kültürü ve Ahlak Bilgisi dersi tutum ölçeğinden alabilecekleri en yüksek puan 19x5=95, en düşük puan 19x1=19'dir. Ölçekte sadece karars1zım seçeneği işaretlendiğinde alınabilecek puan ise $19 \times 3=57$ 'dir.

\section{Verilerin Çözümlenmesi}

Araştırmanın genel amacı ve ana problemi çerçevesinde, uygulanan bütün test ve ölçeklerden elde edilen veriler, her madde için incelenmiş, verilen cevaplar cevap anahtarları ile karşılaştırılarak puanlama yapılmıştır. Denencelere ilişkin toplanan veriler, bilgisayar ortamına aktarılmış ve istatistiksel çözümler için SPSS 16.0 paket programından yararlanılmıştır. Araştırmada elde edilen veriler analiz edilirken uygulama yapılan okullar A (Eyüp Sultan Ortaokulu) ve B (Ahmet Hamdi Tanpınar Ortaokulu) olarak kodlanmıştır. İstatiksel anlamlılık için ise .05 anlamlılık düzeyi seçilmiştir.

Araştırmada; deney ve kontrol grubu öğrencilerinin ön test ve son test fark puanlarına ait ortalama puanlar arasında anlamlı bir farkın olup olmadığını test etmek için normal dağılan puan türlerinde t-testi kullanılmıştır. Bu araştırmada, bağımsız (ilişkisiz) gruplar t-testi; bağımsız iki grup arasındaki (deney-kontrol) farklılıkların incelenmesi için yapılmıştır. Bu test, bağımsız iki grubun ön test, son test, kalıcılık testi, ön tutum ve son tutum ölçümlerinden elde edilen verilerin karşılaştırılmasında kullanılır.

Bağımlı (ilişkili) gruplar t-testi ise; aynı deneklerin deneysel işlemin öncesi ve sonrasında elde edilen ölçümleri arasındaki ilişkiyi görmek için yapılmıştır. Buna göre, araştırmada bağımlı (ilişkili) örneklem t-testi, bir gruba ait ön testson test, ön tutum-son tutum, son test-kalıcılık testi karşılaştırmasını yapmak için kullanılmıştır. Normal dağılmayan puanlar üzerinde, parametrik olmayan testlerden, Mann Whitney U ve Wilcoxon İşaretli Sıralar Testi uygulanmıştır.

\section{Bulgular}

Bu bölümde ise konuyla ilgili yaptığımız alan araştırmasının denencelerine ilişkin verilerin çözümlenmesi sonucu ulaşılan bulgulara ve bu bulgular doğrultusunda yapılan yorumlara yer verilecektir. 


\section{1- A okulu deney ve kontrol grubu öğrencilerinin ön test puanlarına göre başarı düzeylerinin karşılaştırılması}

A okulunda araştırmaya katılan deney ve kontrol grubundaki öğrencilerin deneysel işlem öncesi İbadet Konusunda Bilgilenelim ünitesi başarı testinden ale dıkları ön test puanları, Bağımsız Gruplar t-Testi ile karşılaştırılmıştır. Yapılan analiz sonuçları Tablo 4'da verilmiştir.

$\begin{aligned} & \text { Tablo 4: A Okulu Deney ve Kontrol Gruplarını Ön Test Puanlarına Göre Bağımsız Gruplar t-Testi } \\
& \text { Sonuçları }\end{aligned}$
\begin{tabular}{lllllll} 
Gruplar & N & & S & sd & t & p \\
\hline Deney & 24 & 32,65 & 10,11 & & & \\
Kontrol & 25 & 34,02 & 10,72 & 47 &,- 461 &, 647 \\
\hline
\end{tabular}

Yukarıda Tablo 4'da da görüldüğü gibi, deney grubu öğrencilerinin başarı testi aritmetik ortalamaları $X=32,65$, kontrol grubu öğrencilerinin aritmetik ortalamaları ise $X=34,02$ olarak hesaplanmıştır. Ölçüm puanları karşılaştırılmasın$\mathrm{da}[\mathrm{t}(47)=, 461 ; \mathrm{p}>, 05]$, iki grubun deneysel işlem öncesinde başarı durumları açısından istatistiksel açıdan anlamlı bir fark göstermedikleri görülmektedir. $\mathrm{Bu}$ durum, uygulama yapılan A Okulunda bulunan kontrol ve deney grubu öğrencilerinin deneysel işlem öncesinde, öğrenilecek konuya ilişkin bilgi düzeyleri açısından birbirlerine denk gruplar olduklarını göstermektedir.

\section{2- B okulu deney ve kontrol grubu öğrencilerinin ön test puanlarına göre başarı düzeylerinin karşılaştırılması}

B Okulunda yer alan deney ve kontrol grubundaki öğrencilerin İbadet Konusunda Bilgilenelim ünitesi başarı testinden aldıkları ön test puanları, Bağımsız Gruplar t-Testi ile karşılaştırılmış, yapılan analiz sonuçları Tablo 5'de verilmiştir.

Tablo 5: B Okulu Deney ve Kontrol Gruplarının Ön Test Puanlarına Göre Bağımsız Gruplar t-Testi Sonuçları

\begin{tabular}{|c|c|c|c|c|c|c|}
\hline Gruplar & $\mathrm{N}$ & & $\mathrm{S}$ & sd & $\mathbf{t}$ & $\mathbf{p}$ \\
\hline Deney & 41 & 37,67 & 10,88 & & & \\
\hline Kontrol & 43 & 39,03 & 10,77 & 82 &,- 577 &, 565 \\
\hline
\end{tabular}

Tablo 5'de de görüldüğü gibi, deney grubu öğrencilerinin başarı testi aritmetik ortalamaları $=37,67$, kontrol grubu öğrencilerinin aritmetik ortalamaları ise $=39,03$ olarak hesaplanmıştır. Ölçüm puanları karşılaştırılmasında $[\mathrm{t}(82)=$ -,577; p>,05], iki grubun deneysel işlem öncesinde başarı durumları açısından istatistiksel açıdan anlamlı bir fark göstermedikleri ortaya çıkmıştır. Bu durum, uygulama yapılan B Okulunda bulunan deney ve kontrol grubu öğrencilerinin 
deneysel işlem öncesinde, öğrenilecek konuya ilişkin bilgi düzeyleri açısından birbirlerine denk gruplar olduklarını göstermektedir.

\section{3- A okulu deney ve kontrol grubu öğrencilerinin son test puanları- na göre başarı düzeylerinin karşılaştırılması}

A Okulunda müzik materyalleri kullanılarak oluşturulan öğretim etkinliklerinin uygulandığı deney grubu öğrencileri ile geleneksel öğretim yöntem ve etkinliklerinin uygulandığı kontrol grubu öğrencilerinin deneysel işlem sonrası, son test başarı puanları Bă̆ımsız Gruplar t-Testi ile karşılaştırılmış, elde edilen veriler Tablo 6'de gösterilmiştir.

Tablo 6: A Okulu Deney ve Kontrol Gruplarının Son Test Puanlarına Göre Bağımsız Gruplar t-Testi Sonuçları

\begin{tabular}{|c|c|c|c|c|c|c|}
\hline Gruplar & $\mathrm{N}$ & & $\mathbf{S}$ & sd & t & p \\
\hline Deney & 24 & 54,19 & 19,14 & & & \\
\hline Kontrol & 25 & 42,16 & 15,29 & 47 & 2,435 & ,019 \\
\hline
\end{tabular}

Tablo 6'de de görüldüğü gibi, deney grubu öğrencilerinin başarı testi aritmetik ortalamaları $=54,19$, kontrol grubu öğrencilerinin aritmetik ortalamaları ise $=42,16$ olarak belirlenmiştir. Deney ve kontrol grubuna ait ölçüm puanları karşılaştırılmasında [t(47) $=2,435 ; \mathrm{p}<, 05]$, iki grubun deneysel işlem sonrasında yapılan son test başarı puanlarının gösterdikleri farkın istatistiksel açıdan anlamlı olduğu görülmektedir.

\section{4- B okulu deney ve kontrol grubu öğrencilerinin son test puanlar1- na göre başarı düzeylerinin karşılaştırılması}

B Okulunda müzik materyalleri kullanılarak oluşturulan öğretim etkinliklerinin uygulandığ1 deney grubu öğrencileri ile geleneksel öğretim yöntem ve etkinliklerinin uygulandığı kontrol grubu öğrencilerinin deneysel işlem sonrası, son test başarı puanları Mann-Whitney U Testi ile karşılaştırılmıştır. Testin sonuçları Tablo 7'da görülmektedir.

\begin{tabular}{|c|c|c|c|c|c|}
\hline Gruplar & $\mathbf{N}$ & Sira Ortalaması & Sira Toplamı & $\mathbf{U}$ & $\mathbf{p}$ \\
\hline Deney & 41 & 52,24 & 2142 & & \\
\hline Kontrol & 43 & 33,21 & 1428 & 482 &, 000 \\
\hline
\end{tabular}

Tablo 7'daki bulgular incelendiğinde deney grubunun sıra ortalamasının 52,24 , kontrol grubunun sira ortalamasının 33,21 , P değerinin ise ,000 olduğu 
tespit edilmiştir. Elde edilen bulgular dikkate alındığında (U=482, p<,05), iki grubun deneysel işlem sonrasında yapılan son test başarı puanlarının gösterdikleri farkın, istatistiksel açıdan anlamlı olduğu görülmektedir.

\section{5- A okulu kontrol grubu ögrrencilerinin ön test ve son test puanları- na göre başarı düzeylerinin karşılaştırılması}

A Okulunda, geleneksel öğretim yöntem ve etkinliklerine göre dersin işlendiği kontrol grubu öğrencilerinin ön test ve son test başarı puanları Bağımlı Gruplar $t$-Testi ile karşılaştırılmış ve test sonucu elde edilen veriler Tablo 8' da gösterilmiştir.

Tablo 8: A Okulu Kontrol Grubunun Ön Test ve Son Test Puanlarına Göre Bağımlı Gruplar t-Testi Sonuçları

\begin{tabular}{|c|c|c|c|c|c|c|}
\hline Gruplar & $\mathrm{N}$ & & $\mathrm{S}$ & sd & $\mathrm{t}$ & $\mathrm{p}$ \\
\hline Kontrol Ön Test & 25 & 34,02 & 10,72 & & & \\
\hline Kontrol Son Test & 25 & 42,16 & 15,29 & 24 & $-2,078$ & ,049 \\
\hline
\end{tabular}

Yukarıdaki Tablo 8 incelendiğinde, A okulu kontrol grubu öğrencilerinin deneysel işlem öncesinde aldıkları ön test puanlarının ortalamalarının $=34,02$; deneysel işlem sonrası aldıkları son test puanlarının ortalamalarının ise $=42,16$ olduğu görülmektedir. Her iki ölçüm puanlarının karşılaştırıldığında [t(24) = $-2,078 ; p<, 05]$, kontrol grubunun deneysel işlem öncesi ve deneysel işlem sonrasında başarı durumları açısından istatistiksel olarak anlamlı fark gösterdiği belirlenmiştir.

\section{6- A okulu deney grubu öğrencilerinin ön test ve son test puanlarına göre başarı düzeylerinin karşılaştırılması}

A Okulunda müzik materyalleri kullanılarak oluşturulan öğretim etkinliklerinin uygulandığı deney grubu öğrencilerinin ön test ve son test başarı puanları $\mathrm{Ba}$ ğımlı Gruplar t-Testi ile karşılaştırılmış ve test sonucu elde edilen veriler Tablo 9'de yer gösterilmiştir.

Tablo 9: A Okulu Deney Grubunun Ön Test ve Son Test Puanlarına Göre Bağımlı Gruplar t-Testi Sonuçları

\begin{tabular}{|c|c|c|c|c|c|c|}
\hline Gruplar & $\mathrm{N}$ & & $\mathbf{S}$ & sd & $\mathbf{t}$ & $\mathbf{p}$ \\
\hline Deney Ön Test & 24 & 32,64 & 10,11 & & & \\
\hline Deney Son Test & 24 & 54,18 & 19,14 & 23 & $-5,282$ &, 000 \\
\hline
\end{tabular}

Tablo 9'de de görüleceği üzere, A okulu deney grubu öğrencilerinin deneysel işlem öncesinde aldıkları ön test puanlarının ortalamaları $=32,64$; deneysel işlem 
sonrası aldıkları son test puanlarının ortalamaları ise $=54,18$ olarak hesaplanmıştır. Her iki ölçüm puanlarının karşılaştırılmasında [t(23) = -5,282; $\mathrm{p}<, 05]$, deney grubunun deneysel işlem öncesi ve deneysel işlem sonrasında başarı durumları açısından istatistiksel olarak anlamlı fark gösterdiği görülmektedir.

\section{7- B okulu kontrol grubu öğrencilerinin ön test ve son test puanları- na göre başarı düzeylerinin karşılaştırılması}

B Okulunda, geleneksel öğretim yöntem ve etkinliklerine göre dersin işlendiği kontrol grubu öğrencilerinin ön test ve son test başarı puanlarının karşılaştırılması için Wilcoxon İşaretli Sıralar Testi kullanılmıştır. B okulu kontrol grubunun ön test ve son test puanlarının sonuçları Tablo 10'de yer almaktadır.

$\begin{aligned} & \text { Tablo 10: B Okulu Kontrol Grubunun Ön Test ve Son Test Puanlarına Göre Wilcoxon İşaretli Sıralar } \\
& \text { Testi Sonuçları }\end{aligned}$
\begin{tabular}{llllll} 
Son Test-Ön Test & N & Sıra Ortalaması & Sıra Toplamı & z & p \\
\hline Negatif Sıra & 10 & 20,40 & 204,00 & & \\
Pozitif Sıra & 33 & 22,48 & 742,00 & $-3,251$ &, 001 \\
Eşit & 0 & & & & \\
Toplam & 43 & & & & \\
\hline
\end{tabular}

Tablo 10'de B okulundaki kontrol grubu öğrencilerinin ön test ve son test puanları arasında anlamlı farklılık olduğu ve bu farkın son test puanları lehine $(\mathrm{p}=, 001<, 05)$ olduğu görülmektedir.

\section{8- B okulu deney grubu öğrencilerinin ön test ve son test puanlarına göre başarı düzeylerinin karşılaştırılması}

B Okulunda, müzik materyalleri kullanılarak oluşturulan öğretim etkinliklerinin uygulandığı deney grubu öğrencilerinin ön test ve son test başarı puanlarının karşılaştırılması için Bağımlı Gruplar t-Testi kullanılmıştır. Tablo 11'de B Okulu deney grubunun ön test ve son test puanlarının sonuçları görülmektedir.

$\begin{aligned} & \text { Tablo 11: B Okulu Deney Grubunun Ön Test ve Son Test Puanlarına Göre Bağımlı Gruplar t-Testi } \\
& \text { Sonuçları }\end{aligned}$
\begin{tabular}{lllllll} 
Gruplar & N & S & sd & t & p \\
\hline Deney Ön Test & 41 & 37,67 & 10,88 & & & \\
Deney Son Test & 41 & 61,62 & 15,54 & 40 & $-8,627$ &, 000 \\
\hline
\end{tabular}

Tablo 11 incelendiğinde, B Okulu deney grubu öğrencilerinin deneysel işlem öncesinde aldıkları ön test puanlarının ortalamalarının $=37,67$; deneysel işlem sonrası aldıkları son test ortalamalarının ise $=61,62$ olduğu belirlenmiştir. 
Her iki ölçüm puanlarının karşılaştırılmasında [t(40) $=-8,627 ; \mathrm{p}<, 05]$, deney grubunun deneysel işlem öncesi ve deneysel işlem sonrasında başarı durumları açısından istatistiksel olarak anlamlı bir fark gösterdiği görülmektedir.

\section{9- A okulu deney ve kontrol grubu öğrencilerinin kalıcılık testi pu- anlarına göre başarı düzeylerinin karşılaştırılması}

A Okulunda, müzik materyalleri kullanılarak oluşturulan öğretim etkinliklerinin uygulandığı deney grubu öğrencileri ile geleneksel öğretim yöntem ve etkinliklerinin uygulandığı kontrol grubu öğrencilerinin son test tarihinden yaklaşık bir buçuk ay sonra uygulanan kalıcılık testi başarı puanları Bağımsız Gruplar t-Testi ile karşılaştırılmıştır. Test sonucu elde edilen veriler Tablo 12'de görülmektedir.

Tablo 12: A Okulu Deney ve Kontrol Gruplarının Kalıcılık Testi Puanlarına Göre Bağımsız t-Testi Sonuçları

\begin{tabular}{|c|c|c|c|c|c|c|}
\hline Gruplar & $\mathrm{N}$ & & $\mathbf{S}$ & sd & t & $\mathbf{p}$ \\
\hline Deney & 24 & 48,10 & 18,34 & & & \\
\hline Kontrol & 25 & 37,84 & 13,67 & 47 & 2,227 & ,031 \\
\hline
\end{tabular}

Yukarıda Tablo 12’te de görüldüğü gibi, deney grubu öğrencilerinin son test tarihinden yaklaşık bir buçuk ay sonra uygulanan kalıcılık testi başarı puanlarının aritmetik ortalamaları $=48,10$ olarak hesaplanmış, buna karşılık kontrol grubu öğrencilerinin kalıcılık testi aritmetik ortalamaları ise $=37,84$ olarak tespit edilmiştir.

Buna göre, her iki ölçüm puanlarının karşılaştııılmasında $[\mathrm{t}(47)=2,227$; $\mathrm{p}<, 05]$, deney ve kontrol gruplarının kalıcılık testi başarı durumları açısından istatistiksel olarak anlamlı bir fark gösterdikleri söylenebilir. Ortalama puanlar dikkate alındığında, bu farkın deney grubu lehine anlamlı olduğu görülmektedir. Bu sonuca göre, müzik materyali kullanımının, öğrencilerin öğrendiklerini hatırlama düzeyleri üzerinde, geleneksel öğretim etkinliklerine göre daha etkili bir yöntem olduğu söylenebilir.

\section{0- B okulu deney ve kontrol grubu öğrencilerinin kalıcılık testi pu- anlarına göre başarı düzeylerinin karşılaştırılması}

B Okulunda, deney grubu öğrencileri ile kontrol grubu öğrencilerinin son test tarihinden yaklaşık bir buçuk ay sonra uygulanan kalıcılık testi başarı puanları Mann-Whitney U Testi ile karşılaştırılmıştır. Test sonucu elde edilen veriler Tablo 13 'de görülmektedir. 
Tablo 13: B Okulu Deney ve Kontrol Gruplarının Kalıcılık Testi Puanlarına Göre Mann-Whitney U Testi Sonuçları

\begin{tabular}{llllll}
\hline Gruplar & $\mathbf{N}$ & Sira Ortalaması & Sira Toplamı & U & p \\
\hline Deney & 41 & 53,38 & 2188 & & \\
Kontrol & 43 & 32,13 & 1381 & 435,5 &, 000 \\
\hline
\end{tabular}

Tablo 13'deki bulgular dikkate alındığında, son test tarihinden yaklaşık bir buçuk ay sonra uygulanan kalıcılık testi başarı puanlarının sıra ortalamasının deney grubu öğrencilerinde 53,38; kontrol grubu öğrencilerinde ise 32,13 olduğu görülmektedir. Kalıcılık testinin p değerinin ise ,000 olduğu görülmektedir.

\section{1- A okulundaki deney ve kontrol gruplarının deneysel işlem öncesi Din Kültürü ve Ahlak Bilgisi dersi tutum puanlarının karşılaştırılması}

A Okulundaki deney ve kontrol gruplarının deneysel işlem öncesi Din Kültürü ve Ahlak Bilgisi dersi tutum puanları Mann-Whitney U Testi ile karşılaştııılmıştır. Elde edilen veriler Tablo 14'da yer almaktadır.

Tablo 14: A Okulu Deney ve Kontrol Gruplarının Deneysel İşlem Öncesi Din Kültürü ve Ahlak Bilgisi Dersi Tutum Puanlarına Göre Mann-Whitney U Testi Sonuçları

\begin{tabular}{llllll}
\hline Gruplar & $\mathbf{N}$ & Sira Ortalaması & Sira Toplamı & U & p \\
\hline Deney & 24 & 23,79 & 571 & & \\
Kontrol & 25 & 26,16 & 654 & 271 &, 561 \\
\hline
\end{tabular}

Tablo 14'daki bulgular incelendiğinde deney grubunun sıra ortalamasının 23,79 ; kontrol grubunun sira ortalamasının 26,16 ve $\mathrm{p}$ değerinin ise ,561 olduğu görülmektedir. Tablo 16'daki bulgular dikkate alındığında (U=271, p>,05), iki grubun deneysel işlem öncesinde Din Kültürü ve Ahlak Bilgisi dersi tutum puanlarının istatistiksel açıdan anlamlı bir fark göstermedikleri anlaşılmaktadır.

\section{2- B okulundaki deney ve kontrol gruplarının deneysel işlem öncesi Din Kültürü ve Ahlak Bilgisi dersi tutum puanlarının karşlaştırılması}

B Okulundaki deney ve kontrol gruplarının deneysel işlem öncesi Din Kültürü ve Ahlak Bilgisi dersi tutum puanları, Mann-Whitney U Testi ile karşılaştırılmış ve elde edilen bulgular Tablo 15'de verilmiştir.

Tablo 15: B Okulu Deney ve Kontrol Gruplarının Deneysel İşlem Öncesi Din Kültürü ve Ahlak Bilgisi Dersi Tutum Puanlarına Göre Mann-Whitney U Testi Sonuçları

\begin{tabular}{llllll}
\hline Gruplar & $\mathbf{N}$ & Sira Ortalaması & Sira Toplamı & $\mathbf{U}$ & $\mathbf{p}$ \\
\hline Deney & 41 & 43,56 & 1786 & & \\
Kontrol & 43 & 41,49 & 1784 & 838 &, 697 \\
\hline
\end{tabular}

Tablo 15'deki bulgular incelendiğinde, deney grubunun sıra ortalamasının 43,56; kontrol grubunun sıra ortalamasının 41,49 ve p değerinin ise ,7 olduğu 
görülmektedir. Bu sonuçlar ( $U=838, p>, 05)$, iki grubun deneysel işlem öncesinde Din Kültürü ve Ahlak Bilgisi dersi tutum puanlarının istatistiksel açıdan anlamlı bir fark göstermediklerini ortaya koymaktadır.

\section{3- A okulundaki deney ve kontrol gruplarının deneysel işlem sonrası Din Kültürü ve Ahlak Bilgisi dersi tutum puanlarının karşılaştırılması}

A Okulundaki deney ve kontrol gruplarının deneysel işlem sonrası Din Kültürü ve Ahlak Bilgisi dersi tutum puanları Bağımsız Gruplar t-Testi ile karşılaştırılmıştır. Elde edilen veriler Tablo 16'de verilmiştir.

Tablo 16: A Okulu Deney ve Kontrol Gruplarının Deneysel İşlem Sonrası Din Kültürü ve Ahlak Bilgisi Dersi Tutum Puanlarına Göre Bağımsız Gruplar t- Testi Sonuçları

\begin{tabular}{|c|c|c|c|c|c|c|}
\hline Gruplar & $\mathrm{N}$ & & $\mathbf{S}$ & sd & $\mathbf{t}$ & $\mathbf{p}$ \\
\hline Deney & 24 & 87,41 & 5,37 & & & \\
\hline Kontrol & 25 & 82,04 & 10,45 & 47 & 2,250 & ,029 \\
\hline
\end{tabular}

Tablo 16'e göre, A okulunda bulunan deney grubunun deneysel işlem sonrası Din Kültürü ve Ahlak Bilgisi dersi tutum puanları ortalaması $=87,41$; kontrol grubunun tutum puanları ortalaması ise $=82,04$ olarak hesaplanmıştır. Ölçüm puanları karşılaştırıldığında ise [t(47) =2,250; $<<, 05]$, deney ve kontrol gruplarının deneysel işlem sonrasında Din Kültürü ve Ahlak Bilgisi dersi tutum puanları açısından istatistiksel olarak anlamlı fark gösterdikleri görülmektedir.

\section{4- B okulundaki deney ve kontrol gruplarının deneysel işlem son- rası Din Kültürü ve Ahlak Bilgisi dersi tutum puanlarının karşılaş- tirilmasi}

B Okulundaki deney ve kontrol gruplarının deneysel işlem sonrası Din Kültürü ve Ahlak Bilgisi dersi tutum puanları Bağımsız Gruplar t-Testi ile karşılaştırılmış ve elde edilen bulgular Tablo 17'da kaydedilmiştir.

Tablo 17: B Okulu Deney ve Kontrol Gruplarının Deneysel İşlem Sonrası Din Kültürü ve Ahlak Bilgisi Dersi Tutum Puanlarına Göre Bağımsız Gruplar t- Testi Sonuçları

\begin{tabular}{|c|c|c|c|c|c|c|}
\hline Gruplar & $\mathrm{N}$ & & $\mathbf{S}$ & sd & $\mathbf{t}$ & $\mathbf{p}$ \\
\hline Deney & 41 & 79,87 & 8,24 & & & \\
\hline Kontrol & 43 & 74,20 & 8,13 & 82 & 3,172 &, 031 \\
\hline
\end{tabular}

Tablo 17'a göre, B okulunda bulunan deney grubunun deneysel işlem sonrası Din Kültürü ve Ahlak Bilgisi dersi tutum puanları ortalamas1 $=79,87$; kontrol grubunun tutum puanları ortalaması ise $=74,20$ olarak hesaplanmıştır. Ölçüm puanları karşılaştırıldığında [t( 82$)=3,172 ; \mathrm{p}<, 05]$, deney ve kontrol gruplarının 
deneysel işlem sonrasında Din Kültürü ve Ahlak Bilgisi dersi tutum puanları açısından istatistiksel olarak anlamlı fark gösterdikleri görülmektedir.

\section{5-A okulu deney grubu öğrencilerinin deneysel işlem öncesinde ve sonrasında aldıkları Din Kültürü ve Ahlak Bilgisi dersi tutum puan- larının karşılaştırılması}

A Okulunda, müzik materyalleri kullanılarak oluşturulan öğretim etkinliklerinin uygulandığı deney grubu öğrencilerinin deneysel işlem öncesinde ve sonrasında aldıkları Din Kültürü ve Ahlak Bilgisi dersi tutum puanları, Bă̆ımlı Gruplar t-Testi ile karşılaştırılmıştır. Elde edilen veriler Tablo 18'de görülmektedir.

Tablo 18: A Okulu Deney Grubunun Deneysel İşlem Öncesi ve Sonrası Din Kültürü ve Ahlak Bilgisi Dersi Tutum Puanlarına Göre Bağımlı Gruplar t-Testi Sonuçları

\begin{tabular}{|c|c|c|c|c|c|c|}
\hline Gruplar & $\mathrm{N}$ & & $\mathbf{S}$ & sd & $\mathbf{t}$ & $\mathbf{p}$ \\
\hline Deney Ön Test & 24 & 79,75 & 7,29 & & & \\
\hline Deney Son Test & 24 & 87,41 & 5,37 & 23 & $-3,857$ & ,001 \\
\hline
\end{tabular}

Tablo 18'de yer alan bulgulara göre, A okulunda bulunan deney grubunun deneysel işlem öncesi Din Kültürü ve Ahlak Bilgisi dersi tutum puanları ortalaması $=79,75$; deneysel işlem sonrası tutum puanları ortalaması ise $=87,41$ olarak hesaplanmıştır. Her iki ölçüm puanları karşılaştırıldığında $[\mathrm{t}(23)=-3,857$; $\mathrm{p}<, 05$ ], deney grubu öğrencilerinin deneysel işlem öncesi ve sonrasında Din Kültürü ve Ahlak Bilgisi dersi tutum puanları açısından istatistiksel olarak anlamlı fark gösterdikleri anlaşılmaktadır.

\section{6- B okulu deney grubu öğrencilerinin deneysel işlem öncesinde ve sonrasında aldıkları Din Kültürü Ve Ahlak Bilgisi dersi tutum puanlarının karşılaştırılması}

B Okulunda, müzik materyalleri kullanılarak oluşturulan öğretim etkinliklerinin uygulandığı deney grubu öğrencilerinin deneysel işlem öncesinde ve sonrasında aldıkları Din Kültürü ve Ahlak Bilgisi dersi tutum puanları, Bağımlı Gruplar t-Testi ile karşılaştırılmıştır. Buna göre, elde edilen veriler Tablo 19'de yer almaktadır.

Tablo 19: B Okulu Deney Grubunun Deneysel İşlem Öncesi ve Sonrası Din Kültürü ve Ahlak Bilgisi Dersi Tutum Puanlarına Göre Bağımlı Gruplar t-Testi Sonuçları

\begin{tabular}{|c|c|c|c|c|c|c|}
\hline Gruplar & $\mathrm{N}$ & & $\mathbf{S}$ & sd & $\mathbf{t}$ & $\mathbf{p}$ \\
\hline Deney Ön Test & 41 & 73,56 & 7,56 & & & \\
\hline Deney Son Test & 41 & 79,88 & 8,24 & 40 & $-3,801$ &, 000 \\
\hline
\end{tabular}


Tablo 19'e göre, B okulunda bulunan deney grubunun deneysel işlem öncesi Din Kültürü ve Ahlak Bilgisi dersi tutum puanları ortalaması $=73,56$; deneysel işlem sonrası tutum puanları ortalaması ise $=79,88$ olarak hesaplanmıştır. Her iki ölçüm puanları karşılaştırıldığında [t(40) = -3,801; $p<, 05]$, deney grubu öğrencilerinin deneysel işlem öncesi ve sonrasında Din Kültürü ve Ahlak Bilgisi dersi tutum puanları açısından istatistiksel olarak anlamlı fark göstermektedir.

\section{7- A okulu kontrol grubu öğrencilerinin deneysel işlem öncesinde ve sonrasında aldıkları Din Kültürü ve Ahlak Bilgisi dersi tutum pu- anlarının karşılaştırılması}

A Okulunda, geleneksel öğretim yöntem ve etkinliklerinin uygulandığı kontrol grubu öğrencilerinin deneysel işlem öncesinde ve sonrasında aldıkları Din Kültürü ve Ahlak Bilgisi dersi tutum puanları, Wilcoxon İşaretli Sıralar Testi ile karşılaştırılmıştır.

Tablo 20: A Okulu Kontrol Grubunun Deneysel İşlem Öncesi ve Sonrası Din Kültürü ve Ahlak Bilgisi Dersi Tutum Puanlarına Göre Wilcoxon İşaretli Sıralar Testi Sonuçları

\begin{tabular}{llllll}
\hline Son Test-Ön Test & $\mathbf{N}$ & Sıra Ortalaması & Sıra Toplamı & $\mathbf{z}$ & $\mathbf{p}$ \\
\hline Negatif Sıra & 9 & 14,44 & 130,00 & & \\
Pozitif Sıra & 16 & 12,19 & 195,00 & -876 &, 381 \\
Eşit & 0 & & & & \\
Toplam & 25 & & & & \\
\hline
\end{tabular}

Tablo 20'de, A okulundaki kontrol grubu öğrencilerinin deneysel işlem öncesi ve sonrası Din Kültürü ve Ahlak Bilgisi dersi tutum puanları arasında istatistiksel açıdan anlamlı bir fark olmadığı görülmektedir. $(\mathrm{p}=, 381>, 05)$. Bu sonuca göre, geleneksel öğretim etkinliklerinin, kontrol grubu öğrencilerinin Din Kültürü ve Ahlak Bilgisi dersine karşı tutumlarında herhangi bir fark oluşturmadığ söylenebilir.

\section{8- B okulu kontrol grubu öğrencilerinin deneysel işlem öncesinde ve sonrasında aldıkları Din Kültürü ve Ahlak Bilgisi dersi tutum pu- anlarının karşılaştırılması}

B Okulunda, geleneksel öğretim yöntem ve etkinliklerinin uygulandığı kontrol grubu öğrencilerinin deneysel işlem öncesinde ve sonrasında aldıkları Din Kültürü ve Ahlak Bilgisi dersi tutum puanları, Wilcoxon İşaretli Sıralar Testi ile karşılaştırılmıştır. 
Tablo 21: B Okulu Kontrol Grubunun Deneysel İşlem Öncesi ve Sonrası Din Kültürü ve Ahlak Bilgisi Dersi Tutum Puanlarına Göre Wilcoxon İşaretli Sıralar Testi Sonuçları

\begin{tabular}{llllll}
\hline Son Test-Ön Test & $\mathbf{N}$ & Sira Ortalaması & Sıra Toplamı & $\mathbf{z}$ & $\mathbf{p}$ \\
\hline Negatif Sıra & 17 & 22,85 & 388,50 & & \\
Pozitif Sıra & 26 & 21,44 & 557,50 & $-1,021$ & \multirow{2}{*}{307} \\
Eşit & 0 & & & & \\
Toplam & 43 & & & & \\
\hline
\end{tabular}

Tablo 21'de, B okulundaki kontrol grubu öğrencilerinin deneysel işlem öncesi ve sonrası Din Kültürü ve Ahlak Bilgisi dersi tutum puanları arasında istatistiksel açıdan anlamlı bir fark olmadığı görülmektedir. $(p=, 307>, 05)$.

\section{Sonuç ve Öneriler}

Bu çalışma, müziğin bir öğretim aracı olarak Din Kültürü ve Ahlak Bilgisi derslerinde kullanımının öğrencilerin akademik başarılarına, öğrendiklerinin kalıcılığına ve derse karşı tutumlarına etkisini tespit etmek amacıyla yapılmıştır. 8 hafta 16 saat süren deneysel uygulama sonunda elde edilen verilere dair sonuçları üç başlık altında verebiliriz:

\section{Din Kültürü ve Ahlak Bilgisi Dersinde Müziğin Bir Öğretim Aracı Olarak Kullanıldığı Deney Grubu Öğrencileri ile Öğretmen Kılavuz Kitabında Yer Alan Etkinliklerin Uygulandığı Kontrol Grubu Öğ- rencilerinin Başarılarına İliş̧kin Sonuçlar}

İstatistiksel analiz sonucuna göre, her iki okulda da deney ve kontrol grubu öğrencilerinin ön test puanları arasında anlamlı bir farkın olmadığı, buna göre, grupların deneysel uygulamadan önce öğrenilecek konuya ilişkin bilgi düzeyleri açısından birbirine denk oldukları görülmüştür. Uygulama sonunda yapılan son test ölçümlerinde ise deney grubu öğrencileri ile kontrol grubu öğrencileri arasında Din Kültürü ve Ahlak Bilgisi dersi başarı puanları açısından anlamlı farklı1ık bulunmuştur. Buna göre, müziğin bir öğretim aracı olarak kullanımının deney grubu öğrencilerinin söz konusu ünitedeki kazanımları gerçekleştirme düzeylerini ve akademik başarılarını önemli ölçüde arttırdığı sonucuna ulaşılmaktadir.

Her iki okuldaki deney ve kontrol grubu öğrencilerinin ön test - son test ölçüm puanları grup içerisinde karşılaştırıldığında ise deney grubu öğrencilerinin ortalama puanlarının yüksek oranda arttı̆̆ 
talama puanlarının oldukça az değişim gösterdiği tespit edilmiştir. Bu durum, öğretmen kılavuz kitabında yer alan etkinliklerin öğrencilerin akademik başarılarını artırmada yeterince etkili olmadığını; buna karşın müzik materyali kullanılarak desteklenen eğitim-öğretim sonucunda öğrencilerin öğrenme düzeylerinde önemli bir artışın olduğunu göstermektedir. Din Kültürü ve Ahlak Bilgisi derslerinde öğrencilerin duyguları uyarıldığında, dikkatleri sağlandığında ve motivasyon düzeyi yükseltildiğinde öğrenme durumu en uygun hale gelmektedir. Müziğin ritmik işlevi, öğrencilerin dikkatini ve uyarılmalarını sağlayarak öğrenmenin gerçekleşmesini sağlamaktadır. Ünitenin içeriğini yansıtan müzik parçaları, öğrencilerin sınavlarda başarılı olmalarını sağlamakla birlikte öğrendikleri bilgiyi başka zamanlarda da kullanmalarına yardımcı olmaktadır.

Sonuç olarak, müziğin bir öğretim aracı olarak derslerde kullanımı öğrencilerin akademik başarılarını olumlu yönde etkilemektedir. Bu araştırmada da, müziğin bir öğretim aracı olarak kullanıldığı deney grubu öğrencilerinin söz konusu ünitedeki kazanımları gerçekleştirme düzeylerinin ve akademik başarılarının kontrol grubu öğrencilerine göre önemli ölçüde arttığı tespit edilmiştir. Buna göre, DKAB derslerinde müzik materyali kullanımının öğrencilerin bilgiye ulaşmaları ve akademik başarılarını artırmalarında geleneksel öğretime göre daha etkili olduğu sonucuna ulaşılmıştır. Ayrıca müziğin bir öğretim aracı olarak derslerde kullanımıyla ilgili ulaşılabilen diğer kaynaklar ele alındığında, bu araştırmanın Türkiye'de, alanla ilgili öncü bir araştırma durumunda olduğu söylenebilir.

\section{Deney Grubu Öğrencileri ile Kontrol Grubu Öğrencilerinin Bilgi- lerin Kalıcılık Düzeylerine İlişkin Sonuçları}

Deney ve kontrol gruplarında yer alan öğrencilerin öğrendikleri bilgilerin kalıcılık düzeyleri, yapılan istatistiksel analiz sonucuna göre incelenmiştir. Buna göre, deney ve kontrol gruplarının kalıcılık testi puanları karşılaştırıldığında, kontrol grubu ortalamalarının deney grubu ortalamalarına kıyasla oldukça düşük olduğu gözlemlenmiştir. Her iki okulda yer alan kontrol grubu öğrencilerinin deneysel işlem öncesi aldıkları ön test puanları ile kalıcılık testinden aldıkları puanlar arasında oldukça düşük bir fark bulunmakta, son test puanları ile kalıc1lık testi puanları arasında ise son test lehine anlamlı bir fark bulunmaktadır. Bu durum, kontrol grubu öğrencilerinin, ünitenin hiç işlenmediği ön test düzeyine gerilediklerini göstermektedir. 
Her iki okulda müziğin bir öğretim aracı olarak kullanıldığı deney grubu öğrencilerinin kalıcılık testi puanları ile son test puanları arasında son test lehine anlamlı bir fark bulunmakla beraber, kalıcılık testi ortalamalarının ön test ortalamalarından oldukça yüksek olduğu gözlemlenmiştir. Buna göre, müziğin bir öğretim aracı olarak kullanımının, deney grubu öğrencilerinin öğrendiklerini hatırlama düzeylerini olumlu anlamda etkilediği görülmektedir. Öğretmen k1lavuz kitabına göre ders işlenen kontrol grubu öğrencilerinin ise öğrendiklerini hatırlama düzeylerinin istenilen seviyede olmadığ 1 görülmektedir.

Görüldüğg̈ gibi, müziğin bir öğretim aracı olarak Din Kültürü ve Ahlak Bilgisi derslerinde kullanımı öğrenilen bilgilerin kalıcılığını olumlu yönde etkilemektedir. Bu araştırmada da, müziğin bir öğretim aracı olarak kullanıldığı deney grubu öğrencilerinin öğrendiklerinin kalıcılık düzeyinin kontrol grubu öğrencilerine göre önemli ölçüde arttı̆̆1 tespit edilmiştir. Buna göre, DKAB derslerinde müzik materyali kullanımının öğrencilerin bilgiye ulaşmaları ve akademik başarılarını artırmalarında geleneksel öğretime göre daha etkili olduğu sonucuna ulaşılmıştır.

\section{Deney Grubu Öğrencileri ile Kontrol Grubu Öğrencilerinin Din Kültürü ve Ahlak Bilgisi Dersi Tutumlarına İlişkin Sonuçları}

Araştırmada, müziğin bir öğretim aracı olarak kullanıldığı deney grubu öğrencileri ile öğretmen kılavuz kitabında yer alan etkinliklerin uygulandığı kontrol grubu öğrencilerinin Din Kültürü ve Ahlak Bilgisi dersine yönelik tutumları istatistiksel analizler sonucunda incelenmiştir. Buna göre, her iki okulda da, deney ve kontrol grubu öğrencilerinin deneysel işlem öncesinde söz konusu derse karşı tutumlarının birbirine denk olduğu görülmektedir.

Deneysel işlem sonrası her iki okuldaki deney ve kontrol grubu öğrencilerinin tutum puanlarının deney grubu lehine anlamlı bir fark gösterdiği tespit edilmiştir. Aynı zamanda kontrol grubu öğrencilerinin ön tutum ve son tutum puanları arasında anlamlı bir fark bulunmamaktadır. Bu durumda, öğretmen k1lavuz kitabında yer alan uygulamaların öğrencilerin Din Kültürü ve Ahlak Bilgisi dersine ilişkin tutumları üzerinde herhangi bir fark oluşturmadığı sonucuna varılmaktadır. Deney grubu öğrencilerinin ön tutum ve son tutum puanları arasinda ise son tutum lehine anlamlı bir fark bulunmaktadır. Buna göre, müziğin bir öğretim aracı olarak derslerde kullanımı öğrencilerin derse karşı tutumlarını olumlu yönde etkilemektedir. 


\section{Öneriler}

1. Çalışmamızda elde edilen veriler de göstermektedir ki müzik etkili bir öğretim aracıdır. Teknoloji çağında yaşayan günümüz gençliği, müziğe tarihin herhangi bir döneminden daha çok erişme imkanı bulmaktadır. Müzik ve gençlik arasındaki bu güçlü bağ dikkate alınarak, din derslerinde müzik materyallerine yeterli ölçüde yer verilmelidir.

2. Eğitimbilimi, ilahiyat, gelişim psikolojisi ve musiki alanında uzman olan kişilerin ortak bir çalışma ile öğrencilerin gelişim seviyelerine uygun ve üniteleri içerik ve dil açısından yansıtan müzik parçaları hazırlamaları önerilmektedir.

3. Hazırlanan bu müzik parçalarının bir proje haline getirilmesi ve öğrencilerle aynı yaşlarda olan profesyonel bir müzik grubuna seslendirilmesi önerilmektedir. Aynı zamanda bu müzik materyallerinin dersin öğretmenlerine bir CD ile dağıtılmasının uygun olacağı düşünülmektedir.

4. Hazırlanacak müzik materyallerinin öğrencilerin ilgisini çekecek tarzda olması ve dinî ve ahlaki hassasiyetin de gözetilmesine dikkat edilmesi gerekmektedir.

5. Eğitim ve öğretimin yeniden yapılandırıldığı günümüzde hazırlanacak olan müfredat ve din dersi kitaplarına bu müzik materyallerinin konulması gerekmektedir.

6. Müziğin bir öğretim aracı olarak sadece Din Kültürü ve Ahlak Bilgisi derslerinde değil aynı zamanda Temel Dinî Bilgiler, Arapça, Kur'an-1 Kerim gibi meslek derslerinde de kullanılması amacıyla müzik materyalleri oluşturulmalıdır.

7. Sınıflarda müzik kullanımı, etkili bir sınıf yönetiminin oluşturulmasını sağlamaktadır. Öğretmenlerin çoğu konuların işlenmesinden ziyade, sınıfı nasıl kontrol edeceğinden endişe duymaktadır. Bu nedenle öğretmenler öğrencilerin dikkatini derse çekmek ve davranış problemlerini ortadan kaldırmak amaciyla müziği bir araç olarak kullanabilirler.

\section{Kaynakça}

Alcorta, Candace S. and Sosis, R. (2005). Ritual, emotion, and sacred symbols: the evolution of religion as an adaptive complex. Human Nature. 16(4), 345.

Alkan, C. (1979). Eğitim ortamları. Ankara: Ankara Üniversitesi Eğitim Fakültesi Yayınları.

Arıc1, İ. (2008). Öğrencilerin ilköğretim din kültürü ve ahlak bilgisi dersine yönelik tutumları. Ankara Üniversitesi İlahiyat Fakültesi Dergisi, 13(1), 161-175. 
Aydın, M. Z. (2014). Din öğretiminde resim ve müzikten yararlanma. (2014, 25 Mayıs). Erişim adresi: http://www.mehmetzekiaydin.com/alimalarim/bddlddmsel_toplantilar.html

Başkurt, İ. (2012). Müziğin eğitimde araç olarak kullanılması. İstanbul Üniversitesi İlahiyat Fakültesi. Din ve Müzik Sempozyumu Bildiri Özet Metni, 26-27 Nisan 2012, 41-42.

Berglund, J. (2008). Teaching İslam with music. Ethnography and Education, 3(2), 161-175.

Çilenti, K. (1998). Eğitim teknoloji ve ögretim. Ankara: Kadığlu Matbaası.

Fidan, N. ve Erden, M. (1993). Eğitime giriş. Ankara: Alkım Yayınları.

Kalaycı, Ş. (2009). SPSS uygulamalı çok değişkenli istatistik teknikleri. (4. Baskı). Ankara: Asil Yayınları.

Karasar, N. (2005). Bilimsel araştırma yöntemi. (15. Baskı). Ankara: Nobel Yayınları. Kaya, M. (2001). İlköğretim ve ortaöğretim öğrencilerinin din kültürü ve ahlak bilgisi dersine karşı tutumları. Ondokuz Mayıs Üniversitesi Illahiyat Fakültesi Dergisi, 12, 43-78.

Milli Eğitim Bakanlığı (Komisyon). (2010). Din kültürü ve ahlak bilgisi 5 ögretmen kılavuz kitabı. Milli Eğitim Bakanlığı Yayınları.

Milli Eğitim Bakanlığı (Komisyon). (2013). Din kültürü ve ahlak bilgisi 5 ders kitabı. Milli Eğitim Bakanlığı Yayınları.

Pekgöz, M. ve Hancılar, R. (1972). Eğitimde görme ve işitme araçları. Ankara: Güvendi Matbaası.

Pohlmann, A. (2006). Musik im religionsunterricht der grundschule. Peter Lang Verlag: Frankfurt am Main.

Robin S. (2002). Traces of the spirit: Religious dimension of popular music. New York University Press.

Turgut, M. F. (1977). Ĕgitimde ölçme ve değerlendirme metotlart. Ankara: Nüve Matbaasi.

Uludağ, S. (2002). Din-müzik ilişkisi üzerine. Köprü Dergisi. 79.

Varış, F. (1994). Ĕgitim bilimine giriş. Konya: Atlas Kitabevi.

Yalın, H. İ. (2001). Öğretim teknolojileri ve materyal geliştirme. Ankara: Nobel Yayınları.

Yorulmaz, B. (2012). Bir din eğitimi aracı olarak dini müziğin kullanımı. (2014, 20 Mart). Erişim adresi: http://www.academia.edu/7033998/B._Yorulmaz_ Bir_Din_Egitimi_Araci_Olarak_Dini_Muzigin_Kullanimi_Din_ve_Muzik_Sempozyumu_26-27_Nisan_2012_Istanbul

Zengin, M. (2013). Öğrencilerin din kültürü ve ahlak bilgisi dersine yönelik tutumlarının çeşitli değişkenler açısından incelenmesi. Değerler Ĕ̆itimi Dergisi, 11(25), 271-301. 
Extended Abstract

\section{The Usage of Music as a Teaching Tool in Religion Culture and Moral Knowledge Classes, and Its Effect on Academic Achievement, Attitude and Retention of Knowledge}

Muhammed BABACAN, Corresponding Author, PhD

Candidate, Teaching Assistant.

University of Bristol, Department of Sociology.

E-mail: mb15488@bristol.ac.uk

ORCID: 0000-0002-8845-4677

\section{Introduction}

Music is one of the most important elements of human life, and its aspects reflecting a society's history, beliefs, culture, traditions, values, literature and humour. It has been used as a tool in numerous fields such as the physiological and psychological treatment of people, religious rituals, cultural transmission, communication, adoption of ideologies, advertising and marketing. Considering music as an important component of socio-cultural life, all religions contain it within itself in certain forms and even for most religions, it is of capital importance (Alcorta and Sosis, 2005). Thereby, the music that is used to convey religious meaning and express the influence of religion can be seen as one of the most powerful tools wielded by humanity.

Music materials have been included in religious classrooms of the most Western countries as it has enabled to open new paths in the experience of faith. Religious phenomena and contents have a power that we cannot express with our 
speech habits. In this respect, music not only provides a deeper understanding of religious materials to students but also gives them opportunities to express their feelings and thoughts.

Since 2004, primary education programs in Turkey has been put under a process of renewal in accordance with constructivist approach the way in which an educational understanding which attaches importance to integrating students' in-class and out-of-class learning activities is adopted. In this context, it is seen that there is an emphasis on the relationship between the process of learning in a particular course to other courses.

The usage of music in classrooms creates an effective learning-teaching atmosphere. Such that music materials act as teaching materials developed to enrich educational experiences, facilitate understanding of subjects to be learned and increase teacher's effectiveness (Alkan, 1979). Teaching materials provide opportunity to appeal to more sense organs (Varış, 1994), increase students' interest in subjects (Çilenti, 1998), accelerate learning (Pekgöz ve Hancılar, 1972) and increase its retention (Fidan ve Erden, 1993).

\section{The Research Purpose and Hypotheses}

The starting point of this research is that music influences individuals in almost all aspects and is used in many classrooms as a powerful teaching tool. From this point, the main objective of this research is to answer the following question: "What is the effect of the usage of music materials in religion culture and moral knowledge classrooms on students' academic achievement, retention and attitudes towards the course?"

Accordingly, the following hypotheses were tested to get answers to the problem statement:

1. There is no significant difference between the pre-test achievement scores of the control and experiment group students before the experimental application.

2. There is a significant difference between the post-test achievement scores of the students in the experimental and control groups in favour of the former.

3. There is a significant difference between the pre-test and post-test scores of the students in the experimental and control groups in favour of the post-test.

4. There is a significant difference between the retention test achievement scores of the students in the experimental and control groups in favour of the former. 
5. There is no significant difference between the attitude scores of the students in the experimental and control groups before the experimental application.

6. There is a significant difference between the attitude scores of students in the experimental and control groups in favour of the former.

7. There is a significant difference between the attitude scores of the students in experimental groups before and after the experimental application.

8. There is no significant difference between the attitude scores of the students in control groups before and after the experimental application.

\section{Method}

The research was carried out using quantitative research methods. The quantitative dimension of the research consisted of a mixed experimental research design with pre-test and post-test control group. The experimental design is the field of research in which the desired data is produced to discover the cause-effect relationships between the variables under the control of the researcher. There is always a comparison in every research conducted with experimental research design. This may mean changes within a particular thing or a comparison of the differences between these changes (Karasar, 2005).

In order to increase the sample size of the research, the implementation was carried out in two different schools. The groups were determined as experimental and control groups by random assignment. Teaching was conducted by using music materials in the experimental groups and traditional methods in the control groups.

\section{Experimental Design of the Research}

In the experimental design, participants are evaluated in relation to the dependent variable before and after the experimental application. The pre-test and post-test control group design is, thus, relational because one subject is measured twice over the dependent variable. But at the same time, this design is unrelated due to the comparison of the measurements of the experimental and control groups of different subjects. Therefore, the pre-test and post-test control group design is a mixed design. 


\section{Selection of Experimental and Control Groups}

In order to conduct the experimental research, the socio-cultural and economic characteristics of the schools were considered to reflect the population ideally. As the groups were determined in both schools, the views of teachers in the fields of the religion culture and moral knowledge and school counselling were taken. In addition to this, after determining classes close to each other with learning levels, experimental and control groups were chosen randomly. The sample group consisted of 31 female and 34 male students in the experimental group and 33 female and 35 male students in the control group. Accordingly, the total number of the students participating in the research was 133.

\section{Preparation Process of Music Materials}

Since there were no music materials with regard to the subject discussed in the classrooms, I decided to write five lyrics: "We worship", "It is worship", "Worship concepts", "My dear" and "Prayer". As I wrote the lyrics, I considered their appropriateness for development and educational level of students in the $5^{\text {th }}$ grade and their attainment of the objectives. After taken expert views pertaining to lyrics, they were performed by five students of Scouting and Guiding Federation of Turkey.

\section{Data Collection Tools and Their Developments}

\section{Achievement Test Regarding the Unit 'Let's Learn the Subject of Worship"}

This test was used to measure the students' achievements in the unit 'Let's Learn the Subject of Worship". In the process of preparation, development and implementation of the achievement test, the achievements determined by the Ministry of National Education were firstly taken into consideration. As the achievement test was prepared, similar assessment questions in the textbooks recommended by the Ministry of National Education and in the web sites provided various materials pertaining to religion culture and moral knowledge course were utilized. 


\section{Religion Culture and Moral Knowledge Course Attitude Scale}

"The religion culture and moral knowledge course attitude scale" was developed by Zengin (2013). During the development of the attitude scale, Zengin utilized the attitude scales developed by Kaya (2001) and Arici (2008) as well as the ones prepared in different disciplines.

\section{Data Analysis}

Within the scope of the general purpose and main problem of the research, the data obtained from all tests and scales were examined for each item and the answers were compared with the answer keys and then scored. The collected data was computerized and then SPSS 16.0 software was used for statistical analysis. For statistical significance, .05 significance level was selected. In order to test if there is a significant difference between the mean scores relation to pre-test and post-test gap scores of the experimental and control group students, T-test was used for the normally distributed score types. This test is used to compare the data that is obtained from the pre-test, pro-test, retention test, pre-attitude and post-attitude measurements of two independent groups. Mann Whitney U and Wilcoxon Signed-Rank Test, which are nonparametric tests, were performed on the scores that were not distributed normally.

\section{Results}

\section{Findings Regarding the Academic Achievements of Experimental and Control Group Students}

According to the statistical analysis, there was no significant difference between the pre-test scores of the experimental and control groups students in both schools. In that context, it was identified that the groups were equivalent in terms of knowledge level before the experimental application. At the end of the application, it was found that there is a significant difference between the experimental group students and the control group students in terms of religion culture and moral knowledge course achievement scores.

When the pre-test and post-test measurement scores of the students in both schools were compared, it was found that while the average scores of the experimental group students increased significantly, the average scores of control 
group students showed little change. As a result of these, it is obvious that the usage of music materials as a teaching tool in the classrooms has positively affected students' academic achievement.

\section{Findings on Knowledge Retention of Experimental and Control Group Students}

Retention levels of the students in both groups were examined according to the results of statistical analysis. Accordingly, when the retention test scores of the both groups were compared, it was founded that the average of the control group students was quite low compared to the ones the experimental group students had.

Moreover, there is a significant difference between the retention test scores and post-test scores of the experimental group students in both schools in which music materials was used as a teaching tool. Besides, it was also found that the retention test averages of these students were significantly higher than the pre-test averages. In that sense, it is seen that the usage of the music materials as a teaching too has positively influenced the experimental groups students' retention levels.

\section{Findings Regarding the Attitudes of Experimental and Control Group Students towards the Religion Gulture and Moral Knowledge Course}

Before the experimental application, it was observed that in both schools, the experimental and control group students' attitudes towards the course were equivalent to each other. After the experimental application, it is determined that the attitude scores of the students in both groups indicate a significant difference in favour of the experimental group students. While at the same time, there is no significant difference between the pre-attitude and post-attitude scores of the students in the control group.

\section{Conclusion and Suggestions}

This study was conducted to determine the effect of the usage of music materials as a teaching tool in religion culture and moral knowledge course on students' academic achievement, retention and attitudes towards the course. The results have indicated that there is a significant difference between the ex- 
perimental and control group students' academic achievement, retention and attitude levels in favour of the former. Furthermore, it is found that the usage of music materials in the classrooms has a positive impact on the students' interest, participation and motivation towards the course.

Accordingly, the data obtained in our research has shown that music is an effective teaching tool. The youth living in the age of technology has access to music materials more than any period in history. Considering this powerful link between music and youth, music materials should be adequately included in religious classrooms. The usage of music materials provides effective classroom management. Most teachers are more concerned with how to control the classroom than dealing with the subject to be taught. The usage of music materials can be used to draw students' attention to the subject and eliminate behavioral problems. 
